\title{
A New Powder-pack Carbo-boro-nitriding Process: Microstructural Characterization of Multicomponent Layers on ARMCO® Pure Iron
}

\author{
M. Ortiz-Domínguez¹, L. E. Martínez-Martínez¹, M. A. Flores-Rentería ${ }^{1}$, I. Simón-Marmolejo ${ }^{1}$, M. \\ Elias-Espinosa ${ }^{2}$ \\ 1. Department of Mechanical Engineering, Universidad Autónoma del Estado de Hidalgo-Campus \\ Sahagún, Hidalgo, México. \\ 2. School of Engineering and Sciences, Tecnológico de Monterrey, Ciudad de México, México.
}

The combination of hard surface and resistance to breakage on impact is useful in parts such as a cam or ring gear that must have a very hard surface to resist wear, along with a tough interior to resist the impact that occurs during operation. Further, the surface hardening of steel has an advantage over through hardening, because less expensive low and medium-carbon steels can be surface hardened without the problems of distortion and cracking associated with the through hardening of think sections [1-2]. Nitriding on the surface of ferrous alloys results in the formation of a compound layer of $\gamma^{\prime}-$ $\mathrm{Fe}_{4} \mathrm{~N}_{1-\mathrm{x}}$ and $\varepsilon-\mathrm{Fe}_{2} \mathrm{~N}$ nitrides or a mixture of $\gamma^{\prime}$ and $\varepsilon$ with a nitrogen diffusion zone beneath the nitride layer [3-5]. Likewise, the boriding is a thermochemical treatment in which boron atoms are diffused into the surface of a workpiece and form borides with the base metal, which is performed to increase the hardness, wear and corrosion resistance of these materials in engineering components for industrial applications that require those properties. In case of ferrous alloys, the boride layer may be either a single phase layer $\left(\mathrm{Fe}_{2} \mathrm{~B}\right)$ or a double phase layer $\left(\mathrm{FeB}\right.$ and $\left.\mathrm{Fe}_{2} \mathrm{~B}\right)$ depending on the boron activity in the boriding agent and also on the boriding parameters (time and temperature) depending on the boriding conditions [1,5]. In this study, the microstructure of a mixture of $\gamma^{\prime}-\mathrm{Fe}_{4} \mathrm{~N}_{1-\mathrm{x}}, \varepsilon-\mathrm{Fe}_{2} \mathrm{~N}, \mathrm{Fe}_{2} \mathrm{~B}$ and $\mathrm{CaC}_{2}$ layers formed on an ARMCO pure iron surface have been investigated at different temperatures by the combination of two powders.

Cubic commercial samples were cut from an ARMCO iron bar with composition: $\mathrm{Mn}, 800 \mathrm{ppm}$; $\mathrm{C}$ and $\mathrm{P}, 200 \mathrm{ppm}$; and S, $150 \mathrm{ppm}$. The substrate pure iron used in this work was selected to curb the effect of alloying elements in order to solely analyse the characteristic of a mixture layers and some of their mechanical effects. The carbo-boro-nitriding treatment was carried out in one stage process. The samples were embedded in a closed cylindrical case (AISI 304L stainless steel) the powder mixture having the composition of: $\mathrm{CaCN}_{2}$ (calcium cyanamide) $+\mathrm{CaSi}$ (calcium silicate) $+\mathrm{B}_{4} \mathrm{C}$ (boron carbide) $+\mathrm{SiC}$ (silicon carbide) $+\mathrm{KBF}_{4}$ (potassium fluoroborate). The powder-pack carbo-boro-nitriding process was carried out in a conventional furnace under a pure argon atmosphere at 1223 and $1273 \mathrm{~K}$ for 2 and 8 $\mathrm{h}$ of exposure for each temperature using the same furnace and conditions. The depth of the surface coatings and morphology were analysed by SEM and EDS (JEOL JSM-6360 LV at $20 \mathrm{kV}$ ). X-Ray Diffraction (XRD) analyses of the layers were carried out with $2 \theta$ varying $20^{\circ}$ to $90^{\circ}$, using $\mathrm{CuK} \alpha$ radiation and $\lambda=1.54 \AA$. Figure 1 shows the cross-sections and the EDS analysis obtained by SEM at ARMCO pure iron and Figure 2 shows the cross-sections and the EDS analysis obtained by SEM at surface of the mixture of $\gamma^{\prime}-\mathrm{Fe}_{4} \mathrm{~N}_{1-\mathrm{x}}, \varepsilon-\mathrm{Fe}_{2} \mathrm{~N}, \mathrm{Fe}_{2} \mathrm{~B}$ and $\mathrm{CaC}_{2}$ layers for the carbo-boro-nitrided ARMCO pure iron with a thickness of $500 \mu \mathrm{m}$ approximately. The existence of the $\gamma^{\prime}-\mathrm{Fe}_{4} \mathrm{~N}_{1-\mathrm{x}}, \varepsilon-\mathrm{Fe}_{2} \mathrm{~N}$, $\mathrm{Fe}_{2} \mathrm{~B}$ and $\mathrm{CaC}_{2}$ were verified by X-ray diffraction (Fig. 3). These results demonstrate that the mixture of $\gamma^{\prime}-\mathrm{Fe}_{4} \mathrm{~N}_{1-\mathrm{x}}, \varepsilon-\mathrm{Fe}_{2} \mathrm{~N}, \mathrm{Fe}_{2} \mathrm{~B}$ and $\mathrm{CaC}_{2}$ layers formed on the surface of carbo-boro-nitrided ARMCO pure iron provide high resistance to abrasive wear and corrosion as well as high surface hardness. The combination of a hard surface and softer interior, made possible, for example, by case hardening 
method, is of inestimable value in modern engineering practice. Finally, the $\mathrm{CaC}_{2}$ (Calcium Carbide) layer formed on the surface provides deoxidation (see Fig. 2).

References:

[1] J. R. Davis. "Surface Hardening of Steels: Understanding the Basics“, $1^{\text {st }}$ ed. ASM, Ohio, p. 213.

[2] Z. D. Xiang and P. K. Datta, Surf. Coat. Technol. 179 (2004), p. 95.

[3] K. Y. Li and Z. D. Xiang, Surf. Coat. Technol. 204 (2010), p. 2268.

[4] H. Du and J. Agren, Z. Metallkd. 86 (1995), p. 522.

[5] K. H. Habig, Mater. Eng. 2 (1980) p. 83.

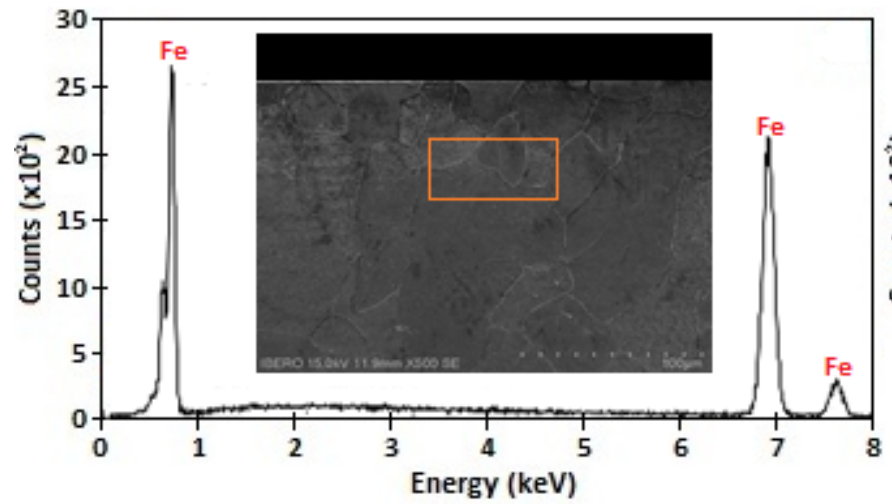

Fig. 1

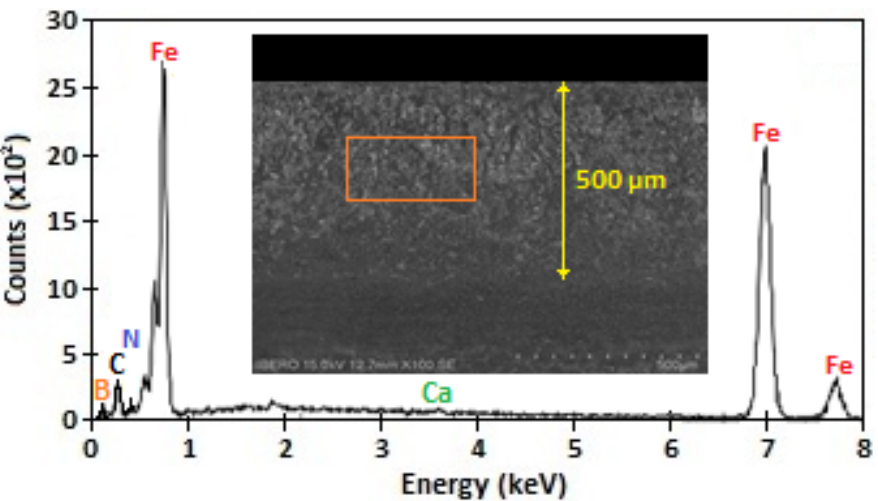

Fig. 2

Figure 1. SEM cross-sectional micrograph and EDS analysis of ARMCO pure iron and SEM (Figure 2) cross-sectional micrograph and EDS spectrum at surface of the mixture of: $\gamma^{\prime}-\mathrm{Fe}_{4} \mathrm{~N}_{1-\mathrm{x}}, \varepsilon-\mathrm{Fe}_{2} \mathrm{~N}, \mathrm{Fe}_{2} \mathrm{~B}$ and $\mathrm{CaC}_{2}$ layers developed on the surface of carbo-boro-nitrided ARMCO pure iron with $1273 \mathrm{~K}$ for 8 h.

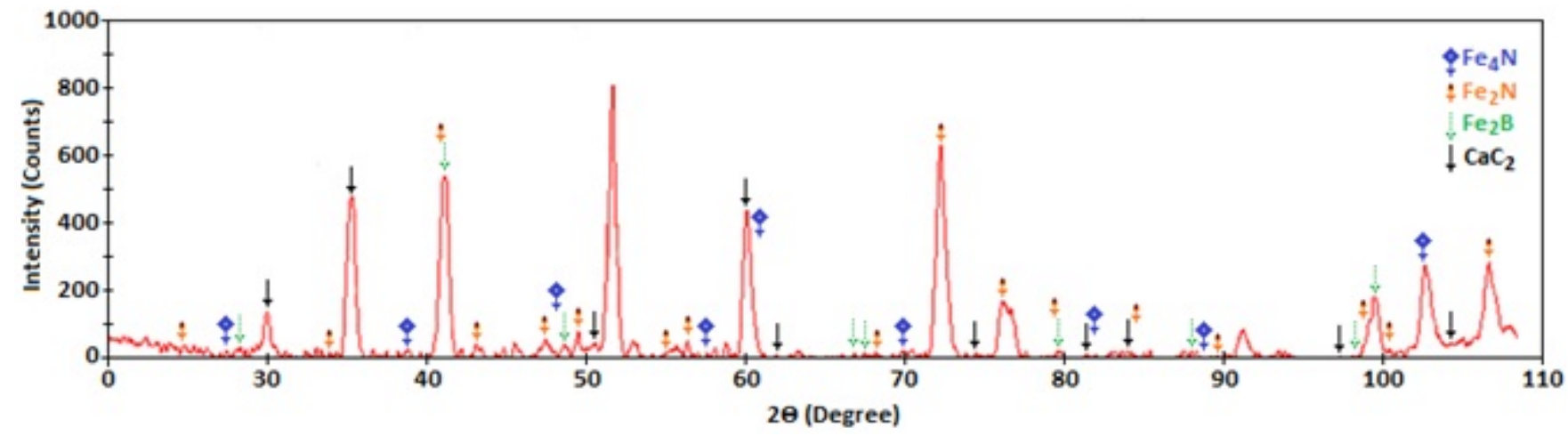

Figure 3. X-ray diffraction patterns obtained at the surface of carbo-boro-nitrided pure iron at a temperature of $1273 \mathrm{~K}$ with $8 \mathrm{~h}$ of exposure time. 